\title{
PENGARUH AKTIVASI ADSORBEN BIOMASSA TERHADAP GUGUS HIDROKSIL PADA PROSES ADSORPSI ION LOGAM TIMBAL (Pb)
}

\author{
Abdurrahman ${ }^{1}$, Suhendrayatna $^{2} *$, Syahiddin DS $^{2}$ \\ ${ }^{1}$ Program Studi Magister Teknik Kimia, Program Pascasarjana Universitas Syiah Kuala \\ ${ }^{2}$ Jurusan Teknik Kimia, Fakultas Teknik, Universitas Syiah Kuala, \\ Jalan Tgk. Syech Abdurrauf No. 7A, Kopelma Darussalam Banda Aceh, Indonesia, 23111 \\ *Email: suhendrayatna@unsyiah.ac.id
}

\begin{abstract}
Abstrak
Logam timbal $(\mathrm{Pb})$ merupakan logam yang sangat populer dan banyak dikenal oleh masyarakat. Hal ini disebabkan oleh penggunaannya yang tinggi di industri dan paling banyak menimbulkan keracunan pada makhluk hidup. Penelitian ini mempelajari proses penyerapan ion $\mathrm{Pb}$ pada air limbah sintetis mengandung ion $\mathrm{Pb}$. Pengamatan difokuskan pada kinerja penyerapan oleh adsorben campuran biomassa tandan kosong kelapa sawit dan sekam padi yang diaktivasi dengan asam sitrat pada berbagai variasi konsentrasi dan mengamati peningkatan bilangan gelombang pada ikatan gugus hidroksil $(-\mathrm{OH})$ setelah diaktivasi dengan asam sitrat. Kinetika adsorpsi terjadi pada bilangan gelombang 3200-3600 $\mathrm{cm}^{-1}$ dimana terlihat kinerja gugus hidroksilnya sangat baik dalam proses penyerapan pada area spektra IR tersebut. Proses penyerapan ion logam Pb terbaik berlangsung pada rasio biomassa (tandan kelapa sawit : sekam padi) 1:1 yang menghasilkan penyerapan sebesar $56,70 \%$ dari konsentrasi awal 80 ppm. Lebih lanjut ditemukan bahwa waktu kontak ion logam $\mathrm{Pb}$ dengan adsorben sangat menentukan hasil penyerapan, semakin lama waktu kontak maka hasil penyerapan semakin baik.
\end{abstract}

Kata kunci : logam berat, timbal, adsorpsi, biomassa, spektra IR

\begin{abstract}
Lead $(\mathrm{Pb})$ is a very popular and widely metal known by public caused by high use in industries and toxid to living organisms. This research was conducted to investigate the absorption process of $\mathrm{Pb}$ ion in synthetic wastewater. The observations focused on the absorption performance by an adsorbent from mixture biomass of palm bunches and rice husk activated with citric acid in various concentrations and observed an increase in the wave number bonding hydroxyl group $(\mathrm{OH})$ after activated with citric acid. Kinetics of adsorption occured at wave number $3200-3600 \mathrm{~cm}^{-1}$ which founded very good performance of hydroxyl groups in the absorption process in that IR spectra area. $\mathrm{Pb}$ ion absorption was found the best on the ratio of biomass (palm bunches: rice husk) 1:1, which occured $56.70 \%$ absorption with initial concentration of $80 \mathrm{ppm}$. Furthermore, it was found that contact time between adsorbent and $\mathrm{Pb}$ ion affect to the absorption.
\end{abstract}

Keywords : heavy metal, Lead, adsorption, Biomass, and FTIR spectra

\section{Pendahuluan}

Pencemaran logam berat sangat berbahaya bagi lingkungan. Banyak laporan yang memberikan fakta betapa berbahayanya pencemaran lingkungan terutama oleh logam berat pada kawasan perairan, baik akibat penggunaan airnya untuk konsumsi sehari-hari maupun ketika mengkonsumsi biota air tawar yang hidup di perairan tercemar tersebut. Kasus yang dilaporkan pertama kali di Jepang, timbulnya penyakit "itai-itai" yang menyebabkan para nelayan dan keluarganya terkena keracunan kronis akibat logam berat Cd dan mengakibatkan kematian manusia 100 orang [5,15]. Lebih lanjut Jaleel [3] menjelaskan bahwa hampir semua industri ditemukan menghasilkan limbah yang mengandung logam berat. Semakin meningkatnya pertumbuhan industri maka peningkatan pencemaran terhadap sumber-sumber air yang berasal dari limbah industri yang dibuang ke perairan tanpa pengolahan terlebih dahulu. Secara umum diketahui bahwa logam berat merupakan elemen yang berbahaya di permukaan bumi. Beberapa unsur logam berat seperti timbal $(\mathrm{Pb})$, kadmium $(\mathrm{Cd})$, merkuri $(\mathrm{Hg})$, arsen (As) dan alumunium (Al) tidak mempunyai fungsi biologi sama sekali bagi manusia. Logam-logam tersebut sangat berbahaya walaupun dalam jumlah yang relatif kecil dan menyebabkan keracunan pada makhluk hidup [10].

Logam timbal $(\mathrm{Pb})$ merupakan logam yang sangat populer dan banyak dikenal oleh masyarakat. $\mathrm{Hal}$ ini disebabkan oleh banyaknya $\mathrm{Pb}$ yang digunakan di industri non pangan dan paling 
banyak menimbulkan keracunan pada makhluk hidup. $\mathrm{Pb}$ adalah sejenis logam yang lunak dan berwarna cokelat kehitaman, serta mudah dimurnikan dari pertambangan. $\mathrm{Pb}$ merupakan logam putih kebiru-biruan dengan pancaran terang yang sangat lunak, mudah dibentuk, ductile, dan bukan konduktor listrik yang baik, namun memiliki resistasi tinggi terhadap korosi.

Studi tentang penyerapan logam berat menggunakan adsorben telah banyak dilakukan dalam berbagai penelitian dan penelitian ke arah tersebut terus dikembangkan [7,14]. Penelitian ini mengamati proses penyerapan ion $\mathrm{Pb}$ oleh biomassa pada air limbah sintetis yang mengandung ion $\mathrm{Pb}$. Pengamatan difokuskan untuk melihat kinerja adsorben campuran biomassa tandan kosong kelapa sawit dan sekam padi yang diaktivasi dengan asam sitrat pada berbagai variasi konsentrasi dan mengamati peningkatan bilangan gelombang pada ikatan gugus hidroksil (-OH) setelah diaktivasi dengan asam sitrat.

\section{Metodologi Penelitian}

Bahan yang digunakan pada penelitian ini meliputi Biomassa (tanda kelapa sawit dan sekam padi) yang diperoleh dari lahan pertanian di Aceh Besar. Semua bahan kimia yang digunakan merupakan bahan murni yang diperoleh secara komersial dari Wako Ltd. Peralatan utama yang digunakan meliputi Muffle Furnace (Line Thermolyne, model: FB1410M-33 at $\left.1100^{\circ} \mathrm{C}\right)$, oven dryer (Memmert), timbangan digital (Ohaus), $\mathrm{pH}$ meter (Oreon), AAS (Atomic Absorption Spectrophotometry; Shimadzu AA-6300), dan FTIR (Fourier Transform Infra Red; Shimadzu IR Prestige 21).

Variabel tetap terdiri dari temperatur pengeringan biomassa $\left(130{ }^{\circ} \mathrm{C}\right)$, volume $\mathrm{NaOH} 0,5$ $\mathrm{N}(500 \mathrm{~mL})$, volume $\mathrm{C}_{6} \mathrm{H}_{8} \mathrm{O}_{7} 100 \mathrm{~mL}$, kecepatan pengadukan $(100 \mathrm{rpm})$, temperatur adsorpsi $\left(30{ }^{\circ} \mathrm{C}\right)$, dan ukuran partikel biomassa (100 mesh). Variabel berubah terdiri dari (1) rasio campuran biomassa (tandan kosong : sekam padi) sebesar: 1:10 (10 gram), 1:5 (15 gram), 1:1 (20 gram), 5;1 (25 gram), dan 10:1 (30 gram); (2) konsentrasi asam sitrat $\left(\mathrm{C}_{6} \mathrm{H}_{8} \mathrm{O}_{7}\right)$ yaitu: $0 \mathrm{~N} ; 0,2 \mathrm{~N} ; 0,4 \mathrm{~N} ; 0,6 \mathrm{~N}$; dan $0,8 \mathrm{~N}$; (3) waktu adsorpsi yaitu: 20 menit, 40 menit, 60 menit, 80 menit, dan 100 menit, dan (4) konsentrasi $\mathrm{Pb}\left(\mathrm{NO}_{3}\right)_{2}$ yaitu: $20 \mathrm{ppm} ; 40 \mathrm{ppm} ; 60 \mathrm{ppm} ; 80$ ppm; dan 100 ppm.

\section{Proses Aktivasi Biomassa}

Sebanyak 15 gram campuran biomassa (rasio biomassa tanda kelapa sawit dan sekam padi sesuai variabel) halus dan kering dicampurkan $\mathrm{NaOH} \mathrm{0,5}$ $\mathrm{N}$ [7,8] pada $500 \mathrm{~mL}$, kemudian dikocok menggunakan shaker dengan kecepatan 100 rpm selama 1 jam pada suhu kamar. Biomassa yang telah dicampur dengan $\mathrm{NaOH}$ kemudian dimasukkan ke dalam $500 \mathrm{~mL}$ aquades dan dikocok pada kecepatan $100 \mathrm{rpm}$ selama 30 menit, cara kerja ini terus diulang sampai diperoleh $\mathrm{pH}=7$ dan dikeringkan pada temperatur $50{ }^{\circ} \mathrm{C}$ selama 2 jam [8].

Biomassa yang telah netral (10 gram) selanjutnya dicampur dengan $100 \mathrm{~mL}$ asam sitrat 0,2 $\mathrm{N}$ dalam $250 \mathrm{~mL}$ erlenmayer dan dikocok dengan shaker pada $100 \mathrm{rpm}$. Setelah 2 jam, biomassa dikeringkan pada temperatur $50{ }^{\circ} \mathrm{C}$ selama 3 jam. Prosedur tersebut diulangi untuk variasi konsentrasi asam sitrat 0,$4 ; 0,6$; dan $0,8 \mathrm{~N}$. Biomassa dipisahkan dari larutannya dengan kertas saring dan dicuci dengan aquades di dalam Buchner Funnel berbasis vakum untuk menghilangkan kelebihan asam sitrat sampai $\mathrm{pH}=7$, dan dilanjutkan dengan pengeringan kembali selama 24 jam pada temperatur $50{ }^{\circ} \mathrm{C} \quad$ [15]. Untuk mengidentifikasi adanya peningkatan jumah gugus hidroksil dari modifikasi dengan asam sitrat ini, biomassa diperiksa menggunakan FTIR.

\section{Proses Adsorpsi}

Proses adsorpsi dilakukan dengan cara mengontakkan 1 gram biomassa yang telah diaktivasi dengan asam sitrat dengan $100 \mathrm{~mL}$ sampel sintetis yang mengandung $20 \mathrm{ppm}$ ion logam $\mathrm{Pb}$ pada $250 \mathrm{~mL}$ erlenmayer. Proses pengontakan dikuti dengan pengadukan menggunakan shaker pada putaran $100 \mathrm{rpm}$ selama selang waktu tertentu (sesuai variasi waktu antara 20-100 menit) pada temperatur $30{ }^{\circ} \mathrm{C}$. Setelah proses penyerapan selesai, konsentrasi ion $\mathrm{Pb}$ pada larutan sampel diambil dan dianalisa menggunakan AAS. Perlakuan tersebut diulangi untuk variasi konsentrasi 40, 60, 80, dan $100 \mathrm{ppm}$.

\section{Prosedur Analisa dengan FTIR}

Sampel biomass sebelum dimodifikasi diuji pada kisaran gelombang inframerah antara $600 \mathrm{~cm}^{-1}$ sampai $4000 \mathrm{~cm}^{-1}$. $\mathrm{KBr}$ digunakan sebagai background dalam analisa sampel padatan. Sebanyak $5 \%$ berat sampel dihomogenkan dengan 95\% $\mathrm{KBr}$ menggunakan mortar dan kemudian ditekan dalam bentuk pellet [12]. Pencucian dengan $\mathrm{NaOH}$ dilakukan untuk sampel yang telah dimodifikasi asam sitrat. Dengan memasukkan 125 mg sampel ke dalam $2 \mathrm{~mL} \mathrm{NaOH} \mathrm{0,1} \mathrm{M} \mathrm{selama} 5$ menit hingga filtratnya mempunyai $\mathrm{pH}$ dengan kisaran 8 sampai 9,5 [4]. 


\section{Hasil}

\section{Karakteristik Adsorben Biomassa}

Karakter kimia suatu adsorben merupakan faktor yang ikut menentukan kemampuan adsorpsi dari adsorben tersebut [4]. Untuk mengetahui karakter adsorben campuran biomassa tandan kosong kelapa sawit dan sekam padi, dilakukan pengamatan dengan menggunakan instrumen FTIR yang hasilnya diilustrasikan pada Gambar 1, 2, dan 3.

Spektra Gambar 1 memperlihatkan serapan melebar pada bilangan gelombang 3200-3600 $\mathrm{cm}^{-1}$ yang menunjukkan serapan akibat vibrasi ulur $\mathrm{O}-\mathrm{H}$ berikatan dengan hidrogen pusat pada $3049,46 \mathrm{~cm}^{-1}$. Gugus -OH adalah gugus hidroksil yang merupakan bagian dari gugus fenol dimana ikatan $\mathrm{O}-\mathrm{H}$ terikat pada senyawa selulosa yang terkandung didalam tandan kosong kepala sawit, hal ini disebabkan karena memiliki nilai bilangan gelombang di atas $3000 \mathrm{~cm}^{-1}$ dan diperkuat oleh serapan $2223,92 \mathrm{~cm}^{-1}$ yang merupakan vibrasi ulur $\mathrm{C}=\mathrm{O}$ yaitu ikatan ester rangkap dua. Penampakan serapan $\mathrm{C}-\mathrm{H}$ ditandai dengan munculnya dua buah pita kuat yang terjadi pada panjang gelombang di bawah $3000 \mathrm{~cm}^{-1}$, untuk bilangan gelombang ikatan $\mathrm{C}-\mathrm{H}$ berkisar antara 2850-2970 $\mathrm{cm}^{-1}$ dari senyawa aromatik yang terkandung di dalam biomassa, kedua pita tersebut adalah pada bilangan gelombang $2926,01 \mathrm{~cm}^{-1}$ dan $2868,15 \mathrm{~cm}^{-1}$. Pita dengan intensitas penyerapan paling kuat terjadi pada bilangan gelombang 2926,01 $\mathrm{cm}^{-1}$ yang disebabkan oleh adanya penyerapan dari gugus $\mathrm{CH}_{2}$, yaitu dari jenis ulur taksimetri $\mathrm{CH}_{2}$. Vibrasi ulur $\mathrm{C}-\mathrm{O}$ dari gugus asam karboksilat terlihat pada panjang gelombang $1066,64 \mathrm{~cm}^{-1}$, gugus ini merupakan bagian dari gugus selulosa dan lignin yang terkandung dalam campuran biomassa tandan kosong kelapa sawit dan sekam padi.

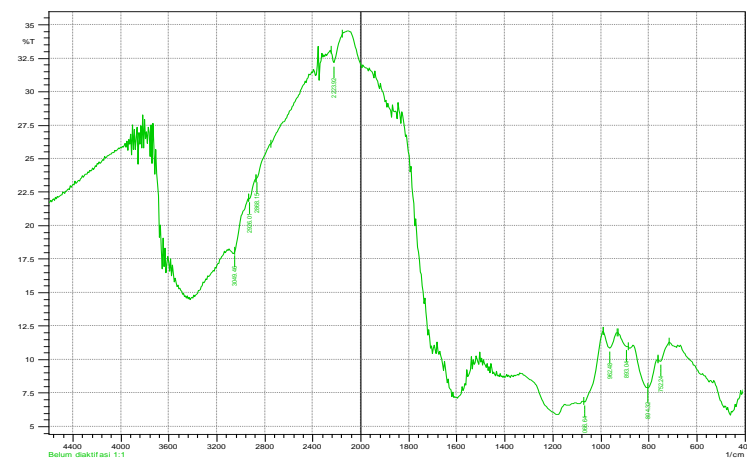

Gambar 1. Spektra FTIR biomassa tandan kosong kelapa sawit dan sekam padi (rasio 1:1) sebelum aktivasi.

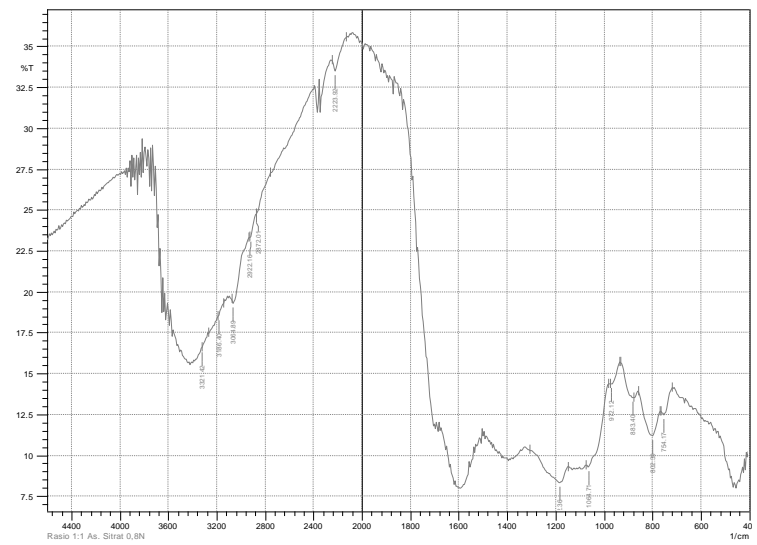

Gambar 2. Spektra FTIR biomassa tandan kosong kelapa sawit dan sekam padi (rasio 1:1) setelah diaktivasi dengan konsentrasi asam sitrat $0,8 \mathrm{~N}$

Gambar 2 memperlihatkan peningkatan panjang gelombang yang disebabkan oleh penambahan asam sitrat konsentrasi $0,8 \mathrm{~N}$. Jika dibandingkan dengan spektra Gambar 1, peningkatan penyerapan yang terjadi tidak besar. Terlihat adanya penambahan bilangan gelombang yang muncul pada spektra Gambar 2 yaitu bilangan gelombang $3186,40 \mathrm{~cm}^{-1}$ dan $3321,42 \mathrm{~cm}^{-1}$ yang diperkirakan merupakan ikatan $\mathrm{O}-\mathrm{H}$ gugus hidroksil dari ikatan hidrogen alkohol yang terikat pada senyawa fenol dengan rentang bilangan gelombang berkisar antara 3200-3600 $\mathrm{cm}^{-1}$. Pada bilangan gelombang 3200-3600 $\mathrm{cm}^{-1}$ menunjukkan serapan akibat dari vibrasi ulur $\mathrm{O}-\mathrm{H}$ berikatan dengan hidrogen pusat pada 3049,46 $\mathrm{cm}^{-1}$. Gugus $-\mathrm{OH}$ adalah gugus hidroksil yang merupakan bagian dari gugus fenol karena memiliki nilai bilangan gelombang di atas $3000 \mathrm{~cm}^{-1}$. Sama halnya pada Gambar 1, penampakan serapan stretching $\mathrm{C}-\mathrm{H}$ pada Gambar 2 ditandai dengan munculnya dua buah pita kuat yang terjadi pada panjang gelombang di bawah $3000 \mathrm{~cm}^{-1}$, untuk bilangan gelombang ikatan C-H berkisar antara 2850-3000 $\mathrm{cm}^{-1}$ dari senyawa alkana yang terkandung di dalam biomassa, kedua pita tersebut adalah pada bilangan gelombang 2922,16 $\mathrm{cm}^{-1}$ dan $2872,01 \mathrm{~cm}^{-1}$ dan nilai pada ikatan alkuna sedikit terjadi kenaikan dan penurunan. Pita dengan intensitas penyerapan paling kuat yaitu pada bilangan gelombang 2922,16 $\mathrm{cm}^{-1}$ yang disebabkan oleh adanya penyerapan dari gugus rocking $\mathrm{CH}_{2}$. Alkohol dan eter mempunyai ciri adsorpsi infra merah karena stretching C-O terjadi di daerah antara 1050-1200 $\mathrm{cm}^{-1}$. Pada Gambar 2 terlihat dua buah pita ikatan C-O yaitu $1064,71 \mathrm{~cm}^{-1}$ dan $1182,36 \mathrm{~cm}^{-1}$, pita dengan intensitas penyerapan paling kuat terjadi pada bilangan gelombang $1182,36 \mathrm{~cm}^{-1}$. 


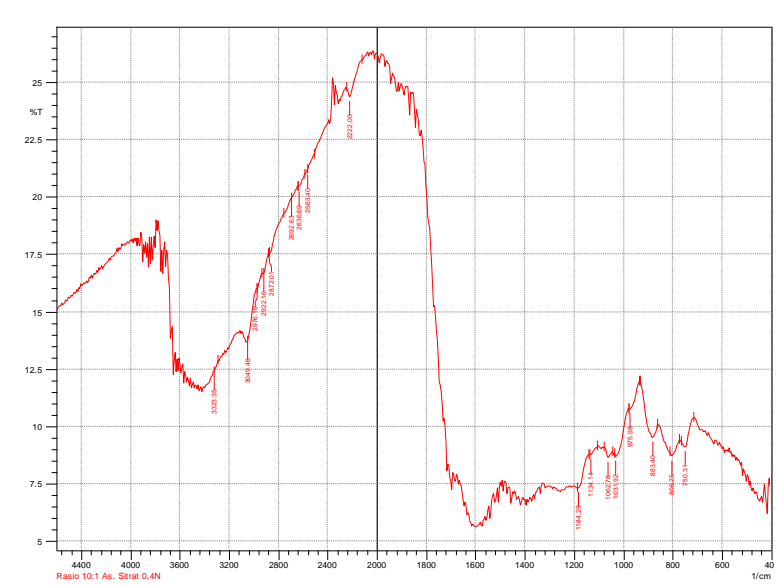

Gambar 3. Spektra FTIR biomassa tandan kosong kelapa sawit dan sekam padi (rasio 10:1) setelah diaktivasi dengan konsentrasi asam sitrat 0,4 $\mathrm{N}$.

Gambar 3 memperlihatkan spektra campuran biomassa kosong kelapa sawit dan sekam padi dengan rasio perbandingan 10:1, dimana campuran terbesarnya adalah komposisi berat tandan kosong kelapa sawit. Gambar 3 memperlihatkan terjadinya peningkatan sangat signifikan, panjang gelombang yang diperkirakan merupakan pita stretching $\mathrm{C}-\mathrm{H}$ terlihat tajam pada bilangan gelombang 3300-3320 $\mathrm{cm}^{-1}$ atau stretching $\mathrm{O}-\mathrm{H}$ yang juga terjadi di daerah bilangan gelombang 3200-3600 $\mathrm{cm}^{-1}$. Menurut penampakan yang terjadi pada bilangan gelombang $3323,35 \mathrm{~cm}^{-1}$, gugus tersebut merupakan ikatan gugus hidroksil dari alkohol pada ikatan fenol dalam senyawa aromatik selulosa. Nilai bilangan gelombang 3049,46 $\mathrm{cm}^{-1}$ juga merupakan gugus hidroksil dari senyawa asam yang ditambahkan ke dalam biomassa sebagai bahan aktivator, penambahan senyawa asam tersebut dengan konsentrasi $0,4 \mathrm{~N}$. Pengaruh penambahan asam sitrat sebagai aktivator sangat menentukan peningkatan nilai bilangan gelombang sehingga daya serapnya akan meningkat dengan meningkatnya nilai bilangan gelombang. Jika dibandingkan dengan spektra Gambar 2, penampakan peningkatan gugus $\mathrm{O}-\mathrm{H}$ memiliki karakteristik yang hampir sama seperti pada Gambar 3, dan jika dilihat dari variasi konsentrasi asam sitrat maka semakin besar penambahan konsentrasi asam sitrat sebagai aktivator maka peningkatan bilangan gelombang ikatan gugus hidroksil akan semakin meningkat sehingga penyerapan akan semakin meningkat pula.

Demikian pula dengan rasio perbandingan biomassa, rasio tandan kosong kelapa sawit lebih baik dengan komposisi berat yang lebih besar dibandingkan dengan sekam padi. Pada spektra Gambar 3 terlihat adanya penambahan bilangan gelombang yang muncul yaitu pada bilangan gelombang 2563,40 cm $\mathrm{cm}^{-1} ; 2636,69 \mathrm{~cm}^{-1}$; dan $2692,63 \mathrm{~cm}^{-1}$, yang diperkirakan juga merupakan ikatan $\mathrm{O}-\mathrm{H}$ gugus hidroksil dari ikatan hidrogen asam karboksilat dengan rentang bilangan gelombang berkisar antara 2500-2700 $\mathrm{cm}^{-1}$ yang merupakan ikatan dari senyawa asam sitrat.

Analisis Rasio Biomassa pada Penyerapan Ion Logam $\mathrm{Pb}$

Penggunaan biomassa sebagai penyerap logam telah banyak digunakan dalam berbagai penelitian penyerapan logam berat, biomassa merupakan energi terbarukan dalam bentuk energi padat yang berasal dari bagian tumbuhan berlignoselulosa baik yang langsung digunakan atau diproses terlebih dahulu [9]. Selama biomassa digunakan sebagai bahan mentah, maka karbonnya dapat dipertahankan di dalam bahan dan tidak memberikan efek kepada emisi gas rumah kaca yang memberikan kontribusi terhadap pemanasan global [6]. Pada penelitian ini biomassa yang digunakan sebagai penyerapan ion logam $\mathrm{Pb}$ yaitu bersumber dari tandan kosong kalapa sawit dan sekam padi, kombinasi kedua biomassa yang digunakan pada berbagai rasio campuran dengan tujuan untuk mengamati seberapa besar daya serapnya terhadap logam berat ion $\mathrm{Pb}$. Kemampuan proses penyerapan biomassa terhadap ion logam $\mathrm{Pb}$ seperti yang ditampilkan pada Tabel 1 dimana proses penyerapan terjadi pada campuran biomassa tandan kosong kelapa sawit dan sekam padi dengan rasio 1:5; 1:1; dan 5:1 dengan berat biomasa masing-masing adalah 15 gram, 20 gram, dan 25 gram. Proses penyerapan berlangsung mulai dari 40 menit, 60 menit, 80 menit dan 100 menit dengan aktivator asam sitrat pada konsentrasi masing-masing $0,4 \mathrm{~N}$ dan $0,6 \mathrm{~N}$.

Tabel 1. Proses adsorpsi logam timbal $(\mathrm{Pb})$ dalam sampel limbah

\begin{tabular}{|c|c|c|c|c|c|}
\hline \multirow{2}{*}{$\begin{array}{c}\text { Rasio } \\
\text { (Berat) }\end{array}$} & \multirow{2}{*}{$\begin{array}{c}\text { Asam } \\
\text { Sitrat } \\
\text { (N) }\end{array}$} & \multirow{2}{*}{$\begin{array}{l}\text { Waktu } \\
\text { (menit) }\end{array}$} & \multicolumn{2}{|c|}{$\begin{array}{c}\text { Konsentrasi Pb } \\
(\mathbf{p p m})\end{array}$} & \multirow{2}{*}{$\begin{array}{c}\% \\
\text { Serapan }\end{array}$} \\
\hline & & & Awal & Akhir & \\
\hline $1: 5$ & 0,6 & 80 & $\begin{array}{l}40 \\
80\end{array}$ & $\begin{array}{l}23,47 \\
43,93\end{array}$ & $\begin{array}{l}41,33 \\
45,09\end{array}$ \\
\hline $1: 1$ & 0,4 & $\begin{array}{c}100 \\
60\end{array}$ & $\begin{array}{c}80 \\
100\end{array}$ & $\begin{array}{l}34,64 \\
59,00\end{array}$ & $\begin{array}{l}56,70 \\
41,00\end{array}$ \\
\hline $5: 1$ & 0,6 & $\begin{array}{l}40 \\
80\end{array}$ & $\begin{array}{l}40 \\
80 \\
\end{array}$ & $\begin{array}{l}21,45 \\
43,39 \\
\end{array}$ & $\begin{array}{l}46,38 \\
45,76 \\
\end{array}$ \\
\hline
\end{tabular}

Berdasarkan hasil penelitian (Tabel 1), proses penyerapan terbaik terjadi pada rasio biomassa 1:1 dimana konsentrasi awal sebelum proses penyerapan masing-masing adalah $80 \mathrm{ppm}$ dan $100 \mathrm{ppm}$. Setelah proses penyerapan berlangsung masingmasing selama 100 menit dan 60 menit, daya serapan biomassa tanda kosong kelapa sawit dan sekam padi yang diperoleh masing-masing pada waktu 100 menit adalah 56,70\% dan waktu 60 menit adalah $41,00 \%$. Lamanya waktu kontak atara adsorbat dengan adsorben sangat mempengaruhi kinerja adsorpsi. Kinetika adsorpsi menggambarkan profil konsentrasi solute selama proses adsorpsi 
sebelum kesetimbangan tercapai, kinetika adsorpsi dipengaruhi oleh faktor berikut: (1) luas permukaan, (2) diameter partikel adsorben, (3) konsentrasi awal, (4) kelarutan adsorbat, (5) berat molekul adsorbat, (6) temperatur, (7) kecepatan pengaduk, (8) pH, dan (9) waktu kontak [1]. Kinetika adsorpsi juga berfungsi untuk menentukan laju pengurangan ion logam berat oleh adsorben di dalam fasa cair pada waktu tertentu.

\section{Kesimpulan}

Kombinasi biomassa tandan kosong kelapa sawit dan sekam padi menjadi alternatif terbaik untuk proses penyerapan ion logam $\mathrm{Pb}$. Pada tahap preparasi dan aktivasi biomassa terjadi peningkatan bilangan gelombang pada ikatan gugus hidroksil ($\mathrm{OH})$ yang dipengaruhi oleh penambahan asam sitrat sebagai aktivator karbon aktif biomassa, nilai bilangan gelombang terbaik terjadi pada rasio biomassa 10:1 dengan konsentrasi asam sitrat adalah $0,4 \mathrm{~N}$. Penyerapan terbaik berlangsung pada rasio biomassa 1:1 dimana daya penyerapan yang dihasilkan adalah 34,64 ppm dari konsentrasi awalnya 80 ppm dengan persentase penyerapan sebesar $56,70 \%$.

\section{Daftar Pustaka}

[1] A. Putranto dan S. Angelina, Thesis, UKP Parahyangan, 2013.

[2] A. M. A. Min, N. F. Kassem, and S.H. Mohamed, Improvement of Cadmium Ion Removal by Base Treatment of Juniper Fiber. Water Res. 38, (2004) 1289-1295

[3] C. A. Jaleel, P. Manivannaa, A. Wahid, M. Farooq, H.J. Al-Jubir, R. Rahmsundaram, and R. Panneerselva, Drought Stress in Plants; A Review on Morfalogical Characteristikcs and Pigments Composistion, International Journal of Agriculture and Biology, 40, (2009) 100105.

[4] J. D. Mc Sweeny, R. M. Rowell, and S. H. Min, Effect of Citric Acid Modification os Aspen Wood on Sorption of Copper Ion. Journal of Natural Fiber, 3, (2006) p.43-58.

[5] J. Soemirat, Toksikologi Lingkungan, Gajah Mada University Press, Yogyakarta, 2005, p. 45.

[6] J. S. Tangio, Thesis, Jurusan Kimia Fakultas MIPA, Universitas Negeri Gorontalo, 2012.

[7] Muhammad, T. G. Chuah, Yunus Robiah, A.R. Suraya, T. S. Y. Choong, Single and Binary Adsorptions Isotherms of $\mathrm{Cd}(\mathrm{II})$ and $\mathrm{Zn}$ (II) on palm kernel shell based activated carbon, Desalination and Water Treatment, 29 (2011) 140-148.

[8] M. Sciban, M. Klasnja, and B. Skrbic, Modified Softwood Sawdust as Adsorbent of
Heavy metal Ions from Water. J. Hazard. Meter. B 136, (2006) 266-271.

[9] M. Arnold, G. Kohlin, R. Perrson, and G. Shepherd, Fuelwood Revisited: What has Changed in the Last Decade, CIFOR Occasional Paper, 39, (2003).

[10] N. S. Indrastri, Suprihatin, Burhanudin, dan Aida, N., 2009. Ph.D Thesis, Fakultas Teknologi Pertanian, IPB, Bogor, 2009.

[11] R. Hastuti, dan Gunawan, Amobilasasi Biomassa Chlorella Sp. pada Silika Gel sebagai Adsorben Tembaga, JSKA, IX (2006).

[12] S. Qaiser, A. R. Saleemi, and M. M. Ahmad, Heavy Metal Uptake by Agro Based Waste Materials. Journal of Biotechnology, 10, (2007) 409-416.

[13] Supriharyono, Pelestarian dan Pengelolaan Sumber Daya Alam di Wilayah Pesisir Tropis, Gramedia Pustaka Utama, Jakarta, 2000, p. 60.

[14] Y. C. Danarto dan Samun, T., Thesis, Jurusan Teknik Kimia, Fakultas Teknik, UNS Surakarta, 2008.

[15] W. E. Marshall, L. H. Wartelle, D. E. Boler, M. M. Jonhs, and C. A. Toles, Enhanced Metal Adsorption by Soybean Hulls Modified with Citric Acid, Bioresourced Technology. 69, (1999) 263-268.

[16] W. E. Marshall, L. H. Wartelle, D. E. Boler, M. M. Jonhs, andC. A. Toles, Metal Ion Adsorption by Soyabean Hulls Modified with Citric Acid: A Comparative Study, Enviromental Technology, 21, (2000) 601-607. 